\title{
SITUAÇÃO DE ESTUDO E ABORDAGEM TEMÁTICA: Relações, Discussões e Sinalizações
}

\author{
Thiago Flores Magoga ${ }^{1}$ \\ Josiane Marques da Silva² \\ Cristiane Muenchen ${ }^{3}$
}

\begin{abstract}
RESUMO
O presente trabalho, de cunho qualitativo, buscou por meio de uma revisão bibliográfica em atas dos Encontros Nacionais de Pesquisa em Educação em Ciências investigar as aproximações e distanciamentos, entre as perspectivas da Abordagem Temática e da Situação de Estudo e, com isso, discutir suas relações com o currículo escolar. O recorte temporal da revisão deu-se no período de 1997 a 2015. A análise dos dados foi baseada na Análise Textual Discursiva e, como principais resultados da pesquisa, destaca-se que a Abordagem Temática está fundamentada na Educação Libertadora Freiriana e a Situação de Estudo no referencial de Vygotsky, mas ambas as perspectivas são identificadas como propostas de reorganização curricular balizadas por temas na intenção de contemplar um ensino interdisciplinar e contextualizado.
\end{abstract}

Palavras-chave: Situação de estudo. Abordagem temática. Currículo escolar.

\section{STUDY SITUATION AND THEMATIC APPROACH: RELATIONS, DISCUSSIONS END SIGNS}

\begin{abstract}
The present work of qualitative searched through a bibliographical revision in National Meeting of Research in Science Education investigate the approximations and distances between the perspectives of the Thematic Approach and the Study Situation, and thereby, to discuss their relations with the school curriculum. The time-cut of there vision occurred in the period from 1997 to 2015. The analysis of the data was based on the Discursive Textual Analysis and as main results of there search, it should be noted that the Thematic Approach is based on Freirean Liberating Education and the Study Situation in Vygotsky's frame ofreference, butboth perspectives are identified as proposals for curricular reorganization guided by themes in order to contemplaten a interdisciplinary and contextualized teaching.
\end{abstract}

Keywords: Study situation. Thematic approach. School curriculum.

Recebido em: $27 / 3 / 2019$

Aceito em: 2/7/2019

\footnotetext{
${ }^{1}$ Graduação em Física (2015) e Mestrado em Educação em Ciências (2017) pela Universidade Federal de Santa Maria (UFSM). Doutorando do Programa de Pós-Graduação em Educação em Ciências: Química da Vida e Saúde (UFSM). http://lattes.cnpq.br/2491174455520382. https://orcid.org/0000-0002-1532-1355. thiago.ufsm@gmai.com

2 Graduação em Física (Unipampa). Mestrado em Ensino de Física e Educação Matemática (UFSM). Doutoranda do Programa de Pós-Graduação em Educação em Ciências Química da Vida e Saúde (UFSM). http://lattes.cnpq.br/4121409440905454. https://orcid.org/00000002-1283-4841. josimarquesilva@gmail.com

3 Doutora em Educação Científica e Tecnológica - Departamento de Física - Centro de Ciências Naturais e Exatas da Universidade Federal de Santa Maria (UFSM - Santa Maria, RS). http://lattes.cnpq.br/0008067199219325. https://orcid.org/0000-0003-3144-0933. crismuenchen@yahoo.com.br
} 
Nos últimos tempos discussões sobre aspectos relacionados ao currículo escolar, principalmente no âmbito do Ensino de Ciências, têm sido recorrentes. Estas discussões problematizam que tais currículos sejam pautados pela interdisciplinaridade, contextualização e abordagem por temas (STRIEDER; CARAMELLO; GEHLEN, 2010; HAMENSCHLAGER, 2011).

A afirmação desses aspectos é constatada, por exemplo, ao se observar o número de trabalhos que têm sido publicados, em cada edição, no principal evento da área - o Encontro Nacional de Pesquisa em Educação em Ciências - assim como alguns eventos específicos, tais como o Simpósio Nacional de Ensino de Física, ou o Encontro Nacional de Ensino de Química, ou ainda o Encontro Nacional de Ensino de Biologia - relacionados, por exemplo, ao eixo relativo ao currículo escolar.

A importância sobre pensar e discutir currículos escolares é destacada por alguns documentos oficiais, a exemplo das Diretrizes Curriculares Nacionais da Educação Básica (DCNEB) (BRASIL, 2013), dos Parâmetros Curriculares Nacionais para o Ensino Médio (PCNEM) (BRASIL, 2000) e mais recentemente da Base Nacional Comum Curricular (BRASIL, 2018).

No mesmo sentido, no âmbito do ensino de Ciências, é possível encontrar na literatura da área autores que discutem e defendem os referidos aspectos, isto é, articulam seus pensamentos e ações a partir da discussão curricular envolvendo diferentes "temas" ou "temáticas". Como exemplo disso destacam-se duas perspectivas que estão em voga na área: a Abordagem Temática (AT) (DELIZOICOV; ANGOTTI; PERNAMBUCO, 2011) e a Situação de Estudo (SE) (MALDANER, 2007).

Apesar de não utilizarem, explicitamente, a denominação "temas transversais", como sugere a Lei de Diretrizes e Bases (LDB), os pesquisadores que utilizam a AT e/ou a SE visam à discussão de processos curriculares - concepção/construção e aplicação por professores, a partir de temas, concebidos de distintas maneiras, em que o papel da interdisciplinaridade, da autonomia docente, do diálogo e da contextualização ganham relativo destaque.

Sendo assim, as duas perspectivas discutem a reorganização do currículo escolar de Ciências - por meios de temas os quais:

[Na proposta da AT, rompem] com o tradicional paradigma curricular cujo princípio estruturante é a conceituação científica, ou seja, um currículo concebido com base numa abordagem conceitual (DELIZOICOV; ANGOTTI; PERNAMBUCO, 2011, p. 189190).

Na proposta de SE visa-se a contemplar as orientações dos PCN; assim, há indicativos de que o trabalho realizado está em consonância com os Temas Transversais e Eixos Temáticos (HALMENSCHLAGER, 2010, p. 40).

Ambas as perspectivas, AT e SE, que possibilitam professores conceber e executar currículos, também tem sido objeto de estudo de diferentes pesquisadores, como: Gehlen (2009), Halmenschlager (2010, 2014), Frison (2012) e Magoga (2017).

A necessidade do estudo, objeto do presente artigo, emergiu das leituras e análises dessas pesquisas, realizadas anteriormente. Percebeu-se que muitos conhecimentos e práticas têm sido produzidos, seja sobre a AT, seja sobre a SE, mas que são poucos 
os trabalhos que discutem, explicitamente, suas relações. Basicamente, os estudos têm apontado análises "isoladas" da AT e "isoladas" da SE, ou, quando em um mesmo trabalho discutem-se ambas as perspectivas, tem se abordado a SE como um tipo, uma modalidade de AT, não havendo aprofundamento no tema.

O que se percebe, portanto, é uma carência de estudos que investiguem, entre outros, certos questionamentos: as bases epistemológicas são as mesmas, entre essas perspectivas? Os autores/pesquisadores que discutem a AT são os mesmos da SE? Os temas da SE possuem mesma característica dos temas da AT? A origem de ambas as perspectivas é a mesma?

Não obstante, reitera-se que a necessidade desse estudo também é apresentada por Magoga (2017) - o qual teve como objetivo caracterizar o Estilo de Pensamento (EP) (FLECK, 2010) a partir dos estudos e práticas de pesquisadores, componentes do círculo esotérico, ${ }^{4}$ da área de Ensino de Ciências - quando o autor percebeu que a SE é um componente importante do EP do coletivo de sujeitos que trabalham com a AT, e, por isso mesmo, apontou para a necessidade de pesquisas que continuassem a tratar de tal assunto.

Desse modo, justifica-se o presente artigo, intitulado "Situação de Estudo e Abordagem Temática: relações, discussões e sinalizações", o qual tem por objetivo investigar as aproximações e distanciamentos entre as perspectivas da AT e da SE e, com isso, discutir suas relações com o currículo escolar.

O objetivo de investigar as possíveis aproximações e distanciamentos entre as perspectivas está calcado na intenção de mapear como os profissionais da área de ensino de Ciências entendem o processo de reorganização curricular em ambas, ou seja, quais elementos que, historicamente, pautam suas discussões.

\section{DESENVOLVIMENTO}

A expressão Abordagem Temática surge, como perspectiva relacionada ao contexto curricular, no livro Ensino de Ciências: fundamentos e métodos, de Delizoicov, Angotti e Pernambuco (2011). Os autores, anteriormente à publicação do livro, trabalhavam teoricamente e a partir de ações práticas - em um viés "contra- hegemônico" ao que vinha sendo, comumente, trabalhado nas aulas de Ciências, nas quais a tônica era a discussão de metodologias fechadas, em que se apresentava uma visão de Ciências fatalista, empirista, individualista e a-histórica, a partir de uma incipiente e tímida discussão sobre "o quê" ensinar, como se este já estivesse dado e o papel dos professores fosse apenas de "aplicar o conteúdo". Nesse viés, o conteúdo era - e ainda é - visto de maneira acabada, como sinônimo de conceito científico.

De forma mais ampla surgem, em meados dos anos 70, alguns movimentos e autores que começaram a questionar as ações curriculares então vigentes (SILVA, 2011). É nesse contexto, portanto, que os autores do livro Ensino de Ciências: fundamentos e

Círculo esotérico é uma terminologia fleckiana (FLECK, 2010) e se refere ao grupo de sujeitos que, vanguardistas, constroem e disseminam conhecimentos e práticas, em relação a determinado objeto de conhecimento. Tal grupo é composto pelo que o autor denomina por "especialistas". 
métodos desenvolviam suas ações - como descrevem, por exemplo, Menezes (1980) e Muenchen e Delizoicov (2014) - de modo que a perspectiva apresentada em tal livro vai de encontro aos questionamentos curriculares oriundos em meados dos anos 70 .

A escrita e publicação do livro, portanto, mais do que a apresentação de "novas ideias", foi um resgate, uma reafirmação, um reolhar sobre trabalhos e ações já desenvolvidos pelos autores. Por isso mesmo, a Abordagem Temática passou a ser entendida, defendida e difundida como sendo "uma perspectiva curricular cuja lógica de organização é estruturada com base em temas, com os quais são selecionados os conteúdos de ensino das disciplinas. Nessa abordagem, a conceituação científica da programação é subordinada ao tema" (DELIZOICOV; ANGOTTI; PERNAMBUCO, 2011, p. 189).

Percebe-se, com isso, que mais do que simplesmente "trabalhar com temas", a AT possui algumas características próprias: trata-se de uma forma de conceber e executar currículos; os conceitos científicos das disciplinas não estão "dados", mas são definidos a posteriori à delimitação dos temas.

Alguns outros autores da área de ensino de Ciências (GEHLEN et al., 2014; FERREIRA, 2016) apontam que a interdisciplinaridade, assim como a contextualização, a problematização e o diálogo também são alguns aspectos importantes e característicos na AT, independentemente da modalidade/referencial epistemológica desta. Para Centa et al. (2015, p. 7):

A Abordagem Temática, como alternativa de organização curricular, pode contribuir no desvelamento de questões sociais, éticas, políticas e econômicas, trabaIhando, assim, de maneira a contribuir com um ensino de ciências que vincula os conceitos científicos aos temas, procurando trazer a realidade dos alunos para a sala de aula, numa perspectiva crítica.

De acordo com Pierson (1997), as diretrizes do que se denomina hoje de AT foram elaboradas e desenvolvidas, inicialmente, por integrantes do Grupo de "Reelaboração de Conteúdo e Formação de Professores", entre os quais estavam os professores Demétrio Delizoicov, José André Peres Angotti e Marta Maria Castanho Pernambuco.

Segundo Magoga e Muenchen (2017), o referido grupo - o qual era locado na Universidade de São Paulo - tinha por base o referencial de Paulo Freire e, por isso, a dialogicidade e a problematização eram características marcantes nas ações executadas. O desenvolvimento dessas ações marcou o pioneirismo do grupo ao transpor as ideias de Paulo Freire para o contexto de educação formal, especificamente para o ensino de Ciências.

Ainda, conforme descrito por Schneider et al. (2014), a base do referencial freiriano para o que se denominou - anos mais tarde - de AT, possibilitava com o que o grupo entendesse e trabalhasse com o cotidiano não como algo acabado, mas algo que "está sendo", impactando, portanto, na construção de currículos escolares e na escolha dos conceitos científicos a serem trabalhados. Por isso mesmo o questionamento central da perspectiva da AT era, e é, o "por que ensinar?", tendo em vista que o cotidiano é um espaço de seleção e organização do conteúdo. Nessa perspectiva, "o que ensinar não é tomado com um dado a priori, como uma escolha consciente onde fatores pedagógicos convivem com fatores epistemológicos e sociais" (PIERSON, 1997, p. 153). 
Ao longo do tempo, com o desenvolvimento de diferentes experiências educativas, reflexões, publicações, a AT foi se constituindo como uma perspectiva de conceber e executar currículos e, paralelamente, foi sendo disseminada entre os pares dentro da área de ensino de Ciências. O trabalho de Magoga et al. (2014), por exemplo, apresenta resultados quantitativos que mostram a presença de práticas educativas relacionadas à AT no principal evento da área de pesquisa em ensino de Ciências. Além da presença dessa perspectiva em pesquisas, percebeu-se, no trabalho supracitado, que ela vem sendo discutida e trabalhada em diferentes etapas de ensino (Fundamental, Médio, e na formação de professores), o que acaba influenciando em sua constituição.

Com o desenvolvimento dessas ações e por suas consequentes publicações, começaram a surgir trabalhos que apontavam para a existência de diferentes "perspectivas" - entendidas também como modalidades - de Abordagens Temáticas, como os de Auler, Dalmolin e Fenalti (2009) e Strieder, Caramello e Gehlen (2010). No mesmo sentido, e para que se possa exemplificar a referida asserção, observa-se a colocação de Hunsche e Delizoicov (2011, p. 2), em que os autores exploram as diferentes propostas educacionais que buscam a organização curricular do ensino de Ciências com base em temas e, por vezes, são denominadas de AT:

[...] dentre as quais se destacam a Abordagem Temática de inspiração freiriana (DELIZOICOV; ANGOTTI; PERNAMBUCO, 2002; DELIZOICOV, 2008), a Situação de Estudo (MALDANER; ZANON, 2001; MALDANER, 2007), a Abordagem Temática com referenciais ligados ao movimento Ciência-Tecnologia-Sociedade (CTS) (SANTOS; SCHNETZLER, 1997; AULER, 2002; GARCÌA; CEREZO; LUJÁN, 1996; SANTOS; MORTIMER, 2000), além da proposta que aproxima referenciais freirianos com os ligados ao movimento CTS (AULER, 2002).

Na medida em que foram ocorrendo tais discussões, publicações e, portanto, consolidações dessas modalidades, pesquisadores como Halmenschlager (2014) também foram efetuando discussões mais amplas sobre as diferentes perspectivas de abordagens por temas, como um todo, entre as quais está a Abordagem Temática. A tese da referida autora apresenta grandes contribuições para a pesquisa em ensino de Ciências, pois nela são efetuadas análises sobre as diferentes abordagens por temas. Ademais, trata-se de um marco histórico importante, sendo este um momento/trabalho em que se estuda, se pesquisa, se debate e se publica, de maneira explícita e profunda, sobre as diferentes formas de conceber e executar currículos escolares.

A constituição e relação entre essas modalidades de trabalhos a partir de temas foram se desenvolvendo na área de ensino de Ciências, de modo que os principais autores/pesquisadores, os quais constroem conhecimento no viés específico da AT, os especialistas - e que, portanto, compõem o que Fleck (2010) denomina de círculo esotérico de sujeitos - percebem, de acordo com Magoga (2017), a recorrência de, basicamente, três modalidades de Abordagens Temáticas: a AT freiriana, a AT na perspectiva CTS e a AT na perspectiva da SE.

A prerrogativa de que essas três modalidades compartilham pressupostos de AT também é apontada por Vieira (2017). Segundo a autora, entretanto, "apesar das propostas de organização curricular serem consideradas como uma abordagem temática, 0 processo de escolha do tema é compreendido de maneira diferente de acordo com os 
referenciais que discutem a proposta da SE, da ATF e CTS" (VIEIRA, 2017, p. 86). Investigar e discutir aspectos associados ao processo de escolha é, portanto, algo que pode ajudar a entender as relações entre cada modalidade específica com a perspectiva curricular da AT. Da mesma forma, talvez seja importante analisar e aprofundar aspectos associados aos referenciais adotados em cada modalidade, em relação à AT.

Na literatura da área de ensino de Ciências atualmente, diferentes são as propostas de trabalhos que utilizam a SE, como se constatará, na sequência, mas que podem ser exemplificados a partir dos seguintes referenciais: Maldaner (2007), Halmenschlager (2011) e Sangiogo et al. (2013).

Dessa distinta gama de trabalhos, talvez o que melhor retrate a SE, a partir de uma análise histórica de constituição e disseminação da proposta, seja o de Vieira (2017). Nesse trabalho a autora analisou a prática de formadores de cursos superiores. Como resultado, observou-se que eles têm trabalhado a proposta da SE em suas disciplinas, a partir de uma perspectiva interdisciplinar e contextualizada, possibilitando a compreensão desta nas interações sociais entre os sujeitos e na articulação com diversas áreas do conhecimento.

Ainda, outro importante trabalho de pesquisa envolvendo a SE foi o de Halmenschlager (2010), em que a autora explicita os critérios adotados para a escolha de temas, nas SEs, desenvolvidas em uma escola de Ensino Médio, vinculada à Unijuí. Como resultado de sua pesquisa, a autora identificou que o principal critério adotado na escolha dos temas para a elaboração de SE era conceitual. Ao final, ela defende que a inserção de alguns aspectos na dinâmica de obtenção dos temas e conceitos, como o reconhecimento da realidade local e a Redução Temática, poderiam complementar a metodologia de escolha dos temas e conceitos na SE, potencializando o processo de ensino-aprendizagem.

Ademais, ao se observar os trabalhos da área, especialmente as análises efetuadas pelas autoras citadas anteriormente, percebe-se que não há uma definição, única, envolvendo a SE (tal qual na AT - DELIZOICOV; ANGOTTI; PERNAMBUCO, 2011 - por exemplo). O que existem são apresentações e discussões de uma proposta educacional, a qual:

[...] exige a participação ativa dos sujeitos, a mediação na construção do conhecimento e, principalmente, a organização curricular de acordo com situações da vivência dos estudantes e professores, de modo a inter-relacionar e significar conceitos científicos, procedimentos, atitudes e valores (PANSERA-DE-ARAÚJO; AUTH; MALDANER, 2007, p. 257).

[...] é conceitualmente rica, identificada nos contextos de vivência cotidiana dos alunos fora da escola, sobre a qual eles têm o que dizer e em cujo contexto eles sejam capazes de produzir novos saberes, expressando-lhes significados e defendendo seus pontos de vista (MALDANER; ZANON, 2001, p. 6).

No entendimento de Auth (2002), a partir da promulgação da LDB de 1996 e das novas orientações dos PCNs, emergiu a necessidade de se repensar propostas pedagógicas na perspectiva de contemplar as novas orientações das políticas públicas. Assim, no contexto do Grupo Interdepartamental de Pesquisas sobre Educação em Ciências (Gipec - Unijuí), foi desenvolvida a ideia de Situação de Estudo. Segundo o referido au- 
tor, a SE "é uma modalidade de organização para desenvolver o processo de ensino/ aprendizagem, a partir de uma situação concreta, de vivência dos alunos, rica conceitualmente para diversos campos das ciências, de forma a permitir uma ação interdisciplinar" (AUTH, 2002, p. 139).

Sob está ótica, faz-se necessário reiterar que os pressupostos epistemológicos da SE estão fundamentados na perspectiva histórico-cultural de Lev Semionovitch Vigotski, a qual, de acordo com Sangiogo et al. (2013), compreende que, justamente, as vivências e as relações do aluno com seu meio são fundamentais na construção do conhecimento, o que, de acordo com as ideias vigotskianas, "possibilita a formação das funções psicológicas superiores, como a capacidade de generalizar e de abstrair" (SANGIOGO et al., 2013, p. 38).

Na perspectiva da abordagem histórico-cultural, portanto, o papel do professor é o de mediador entre o conhecimento científico e o aluno, de modo que a apropriação do primeiro por este último ocorre pela interação com o meio, pela vivência sociocultural de cada indivíduo (HALMENSCHLAGER, 2010, 2014). Por também estar fundamentada em Vygotsky, a linguagem, os sinais, são fundamentais para a constituição do conhecimento, e a constante interação entre sujeitos e contextos faz com que esses sinais ganhem significado e tal significação evolua. Para Maldaner e Zanon (2001, p. 5):

O uso inicial da palavra pelo aprendente significa, apenas, conforme Vygotsky, que o conceito pode começar a evoluir, dependendo das interações que daí por diante acontecerem. É esse princípio que nos levou a propor a organização curricular em sucessivas situações de estudo. Estas permitem que, frente às novas situações, os conceitos possam evoluir e possam ser redirecionados na interação com o professor e em confronto com os textos que passam a participar do contexto em questão.

Desse modo, entende-se que a AT e SE são perspectivas de estruturação curricular, que possuem fundamentos epistemológicos distintos, mas a mesma preocupação de problematizar, na formação inicial e continuada de professores, aspectos que envolvem "o que ensinar?", "como ensinar?" e, principalmente "por que ensinar?"

\section{METODOLOGIA}

Para alcançar o objetivo de investigar as aproximações e distanciamentos entre a SE e a AT, foi realizado um estudo bibliográfico (GIL, 2010) nas atas das dez primeiras edições dos Encontros Nacionais de Pesquisas em Ensino de Ciências (Enpecs), em recorte temporal de 18 anos, de 1997 a 2015. O recorte temporal do estudo bibliográfico deu-se nesse período pelo fato de que se trata dos anos de início do Enpec e do último evento realizado até o começo desta pesquisa.

Argumenta-se que o estudo bibliográfico desenvolvido, nesse primeiro momento, focalizou as produções acadêmicas que abordam a perspectiva da Situação de Estudo, tendo em vista que pesquisas anteriores, descritas em Magoga et al. (2014) e Magoga (2017), já realizaram análises versando sobre a AT. Como já explicitado, no entanto, a discussão dos resultados se dará analisando ambas as perspectivas, conjuntamente. 
Do processo de revisão bibliográfica, conduzido pelo software "Mandeley" foram selecionados 28 trabalhos que continham no título, no resumo e no corpo do texto a expressão "Situação de Estudo". No Quadro 1 são apresentados os títulos dos trabalhos selecionados de acordo com o ano de publicação, bem como a identificação dos estudos utilizada no presente artigo.

A análise dos trabalhos selecionados foi realizada pelo método de fichamento (GIL, 2010), o qual consiste em um sistema de organização das ideias com vista a atender aos objetivos delineados no início da pesquisa. Para tanto foi realizada a leitura na íntegra dos trabalhos selecionados, com a intenção de caracterizar os contextos e como são elaboradas e desenvolvidas as Situações de Estudo na perspectiva de contemplar o objetivo do presente estudo.

Os dados obtidos pelo fichamento foram analisados por meio dos pressupostos da Análise Textual Discursiva (MORAES; GALIAZZI, 2007), organizada em três etapas de análise: (1) Unitarização: caracterizada pela desconstrução dos textos/trabalhos - a partir de releituras e com o auxílio do fichamento - em unidades de significados; (2) Categorização: etapa em que, com o agrupamento das unidades de significado, emergiram as categorias de análise e (3) Comunicação: etapa que consistiu na produção textual em forma de metatextos, os quais serão apresentados na sequência.

Mediante esse processo de análise construíram-se três categorias, classificadas como emergentes e obtidas com base nos dados e informações contidas no fichamento: a) Situação de Estudo como proposta de organização curricular; b) Os temas na Situação de Estudo; c) Contextos de Produção da Situação de Estudo. Sinaliza-se, portanto, que durante a análise, em especial na etapa de Unitarização, foram considerados nos trabaIhos selecionados elementos recorrentes para a construção do fichamento e, a partir disso, na etapa de Categorização, buscou-se mapear e discutir possíveis relações entre os pressupostos da SE com os pressupostos da AT.

Quadro 1 - Disposição dos Títulos dos Trabalhos Selecionados e Identificação

\begin{tabular}{|c|c|c|}
\hline Cód. & Título & $\begin{array}{l}\text { Edição/Ano } \\
\text { do evento }\end{array}$ \\
\hline 1 & $\begin{array}{l}\text { Situação de Estudo como possibilidade concreta de ações coletivas } \\
\text { interdisciplinares no Ensino Médio - Ar Atmosférico. }\end{array}$ & 3/2001 \\
\hline 2 & $\begin{array}{l}\text { A inserção do debate epistemológico no âmbito da educação em } \\
\text { Ciências. }\end{array}$ & $40 / 2003$ \\
\hline 3 & $\begin{array}{c}\text { Significação dos Conceitos de Ciências Naturais e suas Tecnologias numa } \\
\text { Perspectiva Interdisciplinar: análise de uma Situação de Estudo. }\end{array}$ & 5이리 \\
\hline 4 & $\begin{array}{l}\text { Interações de Sujeitos em Formação Para o Ensino de Ciências: } \\
\text { reconstrução social de teorias e práticas docentes. }\end{array}$ & $50 / 2005$ \\
\hline 5 & Contextualização e Significação no Ensino de Ciências Naturais. & 5ㅇ/2005 \\
\hline 6 & $\begin{array}{c}\text { Compreensão das Ciências Naturais como Área de Conhecimento no } \\
\text { Ensino Médio - Conceitos Unificadores. }\end{array}$ & 5 이리 \\
\hline 7 & $\begin{array}{l}\text { O Desenvolvimento de um currículo de Ciências Naturais no Ensino } \\
\text { Médio numa Abordagem contextual e interdisciplinar. }\end{array}$ & $60 / 2007$ \\
\hline 8 & $\begin{array}{l}\text { A Situação de Estudo e a Investigação Temática como Possibilidades de } \\
\text { Formação Continuada. }\end{array}$ & $70 / 2009$ \\
\hline
\end{tabular}




\begin{tabular}{|c|c|c|}
\hline 9 & $\begin{array}{l}\text { Currículo por Área de Conhecimento no Ensino Médio: possibilidades } \\
\text { criadas com situações de estudo nas ciências da natureza. }\end{array}$ & 7이리 \\
\hline 10 & $\begin{array}{c}\text { A Presença da Divulgação Científica no Processo de Ensino-Aprendizagem } \\
\text { do Nível Médio. }\end{array}$ & 7이리 \\
\hline 11 & $\begin{array}{l}\text { Ações de Estagiárias da Licenciatura em Química em Proposta de } \\
\text { Inovação Curricular. }\end{array}$ & 70/2009 \\
\hline 12 & $\begin{array}{c}\text { Drogas: uma proposta de organização curricular que articula formação } \\
\text { docente. }\end{array}$ & 7ㅇ/2009 \\
\hline 13 & $\begin{array}{l}\text { O Papel do Problema em Atividades Didático-Pedagógicas no Ensino de } \\
\text { Ciências. }\end{array}$ & 7이리 \\
\hline 14 & $\begin{array}{l}\text { Problematização no ensino de Ciências: Uma Análise da Situação de } \\
\text { Estudo. }\end{array}$ & 8ㅇ/2011 \\
\hline 15 & $\begin{array}{c}\text { Abordagem de Temas na Perspectiva em Educação em Ciências: } \\
\text { Pressupostos Teóricos-Metodológicos. }\end{array}$ & $89 / 2011$ \\
\hline 16 & $\begin{array}{l}\begin{array}{l}\text { Especificidade no Desenvolvimento de Situação de Estudo: Perguntas do } \\
\text { Professor. }\end{array}\end{array}$ & 8ㅇ/2011 \\
\hline 17 & $\begin{array}{l}\text { Condições de Produção do Conhecimento Escolar: Uma 'Situação de } \\
\text { Estudo' em Foco. }\end{array}$ & 8ㅇ/2011 \\
\hline 18 & $\begin{array}{c}\text { Abordagem Temática no Ensino de Física: Relações entre a perspectiva } \\
\text { vigotskiana e os Momentos Pedagógicos. }\end{array}$ & $89 / 2011$ \\
\hline 19 & $\begin{array}{l}\text { Problematização na Produção da Situação de Estudo “Aquecimento } \\
\text { Global” numa Escola de Ensino Médio. }\end{array}$ & 8ㅇ/2011 \\
\hline 20 & $\begin{array}{c}\text { Automedicação: Um mal necessário? Uma Situação de Estudo Realizada } \\
\text { pelo Pibid/Química-Uesc. }\end{array}$ & 9ㅇ/2013 \\
\hline 21 & $\begin{array}{l}\text { Análise das Principais Tendências em Trabalhos do Ensino de Ciências } \\
\text { sobre a SE. }\end{array}$ & 9 9/2013 \\
\hline 22 & $\begin{array}{l}\text { A Pesquisa como Instrumento Metodológico no Processo de Ensino/ } \\
\text { Aprendizagem. }\end{array}$ & 9이리 \\
\hline 23 & $\begin{array}{l}\text { Pibid/ Química Uesc - Ensinando concentração através de uma Situação } \\
\text { de Estudo no curso técnico de Biotecnologia. }\end{array}$ & 9ㅇ/2013 \\
\hline 24 & $\begin{array}{l}\text { A construção de um terrário como recurso à interdisciplinaridade } \\
\text { no ensino de Ciências: uma proposta fundamentada nos momentos } \\
\text { pedagógicos e na Situação de Estudo. }\end{array}$ & 9ㅇ/2013 \\
\hline 25 & $\begin{array}{c}\text { A Situação de Estudo no processo formativo de licenciados em Química: } \\
\text { algumas contribuições. }\end{array}$ & $10 / 2015$ \\
\hline 26 & $\begin{array}{c}\text { Contribuições da Situação de Estudo ao processo formativo de futuros } \\
\text { professores de Química. }\end{array}$ & $10 / 2015$ \\
\hline 27 & Concepções de estudantes do Ensino Médio sobre Radioatividade. & $10 / 2015$ \\
\hline 28 & $\begin{array}{l}\text { O Ensino-aprendizagem em Ciências com base no tema gerador } \\
\text { combustível fóssil x biocombustível. }\end{array}$ & $10 / 2015$ \\
\hline
\end{tabular}

Fonte: Os autores.

\section{RESULTADOS E DISCUSSÕES}

Como referido anteriormente, após a seleção dos trabalhos foram realizadas leituras e análises para que se pudesse observar elementos característicos à $\mathrm{SE}$, em comparação ao que a literatura da área aponta sobre a AT. Dessa forma, a convergência de diferentes elementos dessas análises possibilitou a constituição de três categorias, as quais serão apresentadas e discutidas na sequência. 
Para facilitar o entendimento sobre os aspectos apresentados em cada uma das três categorias, preferiu-se iniciar as discussões sobre os elementos derivados das análises e, ao final de cada categoria, explorar as relações com aspectos da AT. Reitera-se, ademais, que apesar de o título das categorias explicitarem apenas a SE, elas serão descritas a partir da articulação com elementos da AT, conforme o objetivo do trabalho.

\section{Situação de Estudo Como Proposta de Organização Curricular}

A primeira categoria, como a própria denominação sugere, é composta por elementos oriundos dos trabalhos que apontam para a estreita relação entre a perspectiva da Situação de Estudo e os currículos escolares.

Obviamente que tal relação não é, ou não deve ser entendida, de modo simplista, em que, por exemplo, haja apenas sucintas inserções. O que se percebeu é o fato de as Situações de Estudos envolverem uma concepção de processo de ensino/aprendizagem amplo, na qual o planejamento e papel do professor são fundamentais para o concebimento de "outro" currículo. As unidades de significado, a seguir, mostram a concepção dos autores em relação à SE como perspectiva curricular e, portanto, justificam a denominação da categoria:

Em nossa busca de outras possibilidades de educação em Ciências, temos procurado inserir as ideias de produção e validação da Ciência como nova organização curricular, na forma de Situações de Estudo (SEs) (Trabalho 2, p. 2, grifo nosso).

Os resultados da pesquisa permitem-nos argumentar em favor dessa proposta curricular de SE, na melhoria da qualidade do ensino de Ciências. A partir do exposto, propomos continuidade nas pesquisas nesse campo de conhecimento, para contribuir com a comunidade educativa, demonstrando novas potencialidades da Organização Curricular com Base em Sucessivas Situações de Estudo (Trabalho 6, p. 11, grifo nosso).

O entendimento da SE como uma perspectiva de pensar e executar currículos, de uma forma mais ampla, também é compartilhado em outros trabalhos da área, por exemplo em Sangiogo et al. (2013, p. 39), no qual se percebe a necessidade de "romper a estrutura curricular disciplinar do Ensino Médio, no que tange à ruptura entre as disciplinas de uma mesma área bem como à sequência de conteúdos tradicionalmente trabalhados em cada disciplina".

Assim como a SE, a AT tem sido definida - como já explicitado anteriormente como uma perspectiva curricular ampla, na qual haja, por exemplo, trabalhos de grupos específicos, articulando suas ações à formação de professores (MAGOGA, 2017).

Caracterizar a SE dessa forma mostra que tanto ela quanto a AT referem-se ao mesmo objeto, compartilhando premissas básicas de reorganização curricular, e as colocam em posição de equivalência, isto é, talvez antes de a SE ser uma possível modalidade, específica, de AT, ela ocupa um status tal qual esta última, e, além disso, a coloca distante de uma "simples" abordagem por temas, as quais são marcadas por inserções pontuais, sem reflexões curriculares mais amplas. 
Ainda, tratando-se da relação entre a SE e os currículos escolares, decorre outro importante elemento constitutivo do processo de ensino/aprendizagem: o trabalho articulado de maneira dialógica entre as disciplinas, ou, dito de outra forma, a interdisciplinaridade. Pensar em "outra forma" de organização curricular implica, necessariamente, repensar o papel das disciplinas, isoladas e conjuntamente. A interdisciplinaridade, portanto, ganha centralidade.

Durante as análises percebeu-se relativa menção à interdisciplinaridade - na condição de perspectiva teórica - e ao trabalho interdisciplinar - como ação prática. De todos os artigos, apenas no trabalho 18 não há, pelo menos, menção ao trabalho interdisciplinar. No restante percebeu-se tanto menção à interdisciplinaridade, quanto sinalizações e ações desenvolvidas, conjuntamente, por mais de uma disciplina.

Na perspectiva da SE, entretanto, a menção à interdisciplinaridade e ao trabalho interdisciplinar tem ficado restrito, quase que de forma unânime, às ditas Ciências da Natureza (Biologia, Física e Química). Observa-se, por exemplo, as seguintes descrições:

As transcrições das videogravações, produções textuais e cópias de avaliações referentes à sistematização da SE, envolvendo os componentes de Biologia, Física e Química permitiram identificar os conceitos mais representativos, como se inter-relacionam e como se tornam inter e transdisciplinares (Trabalho 9, p. 4).

Se, então, os participantes da proposição de uma SE são de componentes disciplinares diversos, como os professores da área de conhecimento de uma escola, a construção do conhecimento e, principalmente, a organização curricular de acordo com situações da vivência dos estudantes e professores acontecem mediações com diversos níveis de assimetria, segundo referencial teórico adotado, de modo a inter-relacionar e significar conceitos científicos, procedimentos, atitudes e valores dentro de uma área do conhecimento, no caso, Ciências da Natureza e suas Tecnologias (CNT) (Trabalho 16, p. 3).

De acordo com Muenchen (2006), a interdisciplinaridade também é um componente importante na perspectiva da AT, o que, portanto, estreita sua aproximação com a SE. Para Auler (2003, p. 11), por exemplo,

na perspectiva da abordagem temática, os temas, por se constituírem de situações amplas, complexas, permitem, requerem uma abordagem interdisciplinar, menos fragmentada [...]. Os temas, expressando fenômenos sociais complexos, remetem ao interdisciplinar. Sua compreensão requer vários campos de conhecimento, inclusive aqueles não restritos ao escopo das ciências naturais. Em síntese, o tema representa o ponto de encontro interdisciplinar das várias áreas do saber.

Percebe-se, com isso, que tanto a SE quanto a AT discutem e preconizam a interdisciplinaridade, articulando-a à estruturação do currículo escolar. Parece, contudo, haver um elemento diferenciador entre ambas: enquanto na AT - como resumidamente apresentado na citação de Auler (2003), mas também percebido em Schneider et al. (2014) e em Centa et al. (2015) - há, pelo menos, menção a outras áreas do conhecimento, na SE - pela análise dos trabalhos do Quadro 1 - o trabalho prático e a menção ficam quase que sumariamente restritos à área das Ciências da Natureza. 
Da análise dos trabalhos, as exceções à colocação anterior são os artigos 10 e 17. Nesses há o desenvolvimento de ações em que professores de Matemática e Geografia, respectivamente, executaram conjuntamente com professores das Ciências Naturais e Exatas. Entende-se, com isso, a possível "falta" e a necessidade de contribuições derivadas das ditas Ciências Humanas, de forma mais sistemática e integrada. A busca por um diálogo entre as Ciências Naturais e Exatas e as Ciências Humanas é alertada por Auler, Dalmolin e Fenalti (2009, p. 80), ao discutirem aspectos associados à AT:

Apesar de avanços significativos na busca de superação da fragmentação disciplinar, o estudo, a análise de temas de relevância social, apenas do ponto de vista das assim chamadas ciências naturais, pode resultar numa recaída cientificista. Os alunos, sistematicamente analisando temas sociais unicamente a partir dos óculos deste campo de conhecimento, poderão construir a compreensão de que tal campo é suficiente para compreender e buscar soluções para problemas sociais marcados pela dimensão científico-tecnológica.

Apesar de tal constatação, o elemento aglutinador entre as perspectivas da AT e da SE continua sendo a interdisciplinaridade, como premissa básica para os trabalhos com temas, a partir de uma reconstrução curricular. Não obstante, portanto, a interdisciplinaridade é uma importante justificativa para o desenvolvimento das ações nesses vieses. Isto é, ao buscar uma resposta para a questão "Por que reestruturar os currículos escolares?", tanto nos trabalhos analisados sobre SE quanto na literatura da área, para a AT, percebeu-se a recorrência de elementos que justificam a superação da fragmentação curricular, em busca de um ensino contextualizado e interdisciplinar. Dos trabalhos do Quadro 1, versando sobre a SE:

Trata-se de uma organização do ensino que parte da identificação e exploração de recortes da vivência dos estudantes, conceitualmente ricos para as diversas ciências que assume características disciplinares, interdisciplinares e contextuais, atendendo demandas da sociedade contemporânea (Trabalho 4, p. 2, grifo nosso).

Ao propormos a situação de estudo como abordagem pedagógica adequada da área científica no ensino médio, estamos rompendo com práticas tradicionais de organização curricular, com base em disciplinas separadas desenvolvidas de forma fragmentada e linear (Trabalho 1, p. 8, grifo dos autores).

A discussão de elementos contextuais e a busca da superação disciplinar são, também, elementos constitutivos da AT, sendo objetos de justificativa de diferentes trabaIhos, como no de Menezes (1980) - em que o autor coloca a necessidade de incorporar aspectos do cotidiano do aluno ao currículo escolar na tentativa de superar o, hoje, chamado ensino propedêutico, além de defender o ensino de Física articulado com o ensino de História, Economia e Sociologia. Mais recentemente, trabalhos como o de Muenchen e Auler (2007) e Giacomini e Muenchen (2017) têm defendido tais premissas da AT baseando-se, também, nos documentos oficiais.

A discussão dos aspectos apresentados nessa categoria mostra semelhanças e diferenças entre a SE e a AT, o que, entretanto, não deve ser visto como um juízo de valor a respeito das perspectivas em si, ou sequer aos trabalhos que versam sobre elas. Tais 
relações (aproximações e distanciamentos), colocadas no âmbito curricular, podem ser apresentadas de modo sintético - mas não devem ser vistas de modo simplista - no Quadro 2.

Quadro 2 - Síntese da Categoria "Situação de Estudo Como Proposta de Organização Curricular"

\begin{tabular}{|l|l|}
\hline \multicolumn{1}{|c|}{ Situação de Estudo } & \multicolumn{1}{c|}{ Abordagem Temática } \\
\hline $\begin{array}{l}\text { Mais ampla que uma metodologia: é } \\
\text { proposta curricular }\end{array}$ & $\begin{array}{l}\text { Mais ampla que uma metodologia: é uma } \\
\text { proposta curricular }\end{array}$ \\
\hline $\begin{array}{l}\text { Busca um ensino contextualizado e } \\
\text { interdisciplinar }\end{array}$ & $\begin{array}{l}\text { Busca um ensino, além de contextualizado } \\
\text { e interdisciplinar, problematizador e } \\
\text { transformador }\end{array}$ \\
\hline $\begin{array}{l}\text { Interdisciplinaridade: especialmente entre as } \\
\text { disciplinas da área de Ciências da Natureza }\end{array}$ & $\begin{array}{l}\text { Interdisciplinaridade: menção ao trabalho } \\
\text { entre as diferentes áreas }\end{array}$ \\
\hline
\end{tabular}

Fonte: Os autores.

\section{Os Temas na Situação de Estudo}

A segunda categoria, intitulada "Os Temas na Situação de Estudo", continua a analisar um importante aspecto da perspectiva, a qual possui relações com o currículo escolar, mas merece um destaque especial: os conceitos e conteúdos, os assuntos, os temas abordados pela SE.

Os 28 artigos do Quadro 1 são unânimes e colocam a SE como uma perspectiva de trabalho a partir de temas, como exemplificam os trechos a seguir:

Com Situações de Estudo, a realização de atividades curriculares escolares é proposta com base em estudo por temas. Estudo é o compromisso de professores e estudantes desde o início na busca da compreensão da situação ou do tema proposto. Por ser uma situação prática, isto é, do mundo real (natural, tecnológico, social), a compreensão exige a abordagem de diversas dimensões que se cruzam no tema (Trabalho 9, p. 3).

[...] Situação de Estudo (SE), alternativa curricular organizada a partir de temáticas e balizada nos pressupostos da abordagem histórico-cultural (Trabalho 14, p. 1, grifo nosso).

O trabalho a partir de temas, além de estar sugerido em documentos oficiais, apresenta contribuições tanto ao professor quanto ao aluno, pois o primeiro assume um papel de construtor de currículos, pesquisador, agente do processo (HUNSCHE, 2010), enquanto o segundo apresenta reflexões em sua aprendizagem, passa a situar-se criticamente, vê-se sujeito de sua aprendizagem (DELIZOICOV; ANGOTTI; PERNAMBUCO, 2011).

A discussão desses temas, entretanto, na SE, encontra relação com a categoria anterior: não são quaisquer temas, mas aqueles que possibilitam uma reestruturação do currículo, o que - de certa forma - encontra semelhanças com a AT, pois esta última é definida, justamente, como uma perspectiva de trabalhos a partir de temas. 
Após as leituras e análises dos 28 artigos, os quais são tanto de natureza teórica quanto prática, ${ }^{5}$ identificaram-se 12 temas, destacando-se que em alguns trabalhos eles são denominados de "temática" ou mesmo "Situações de Estudos".

Interessante notar, porém, a natureza desses temas/temáticas/Situações de Estudo, ou seja, a forma como eles são concebidos, escolhidos. Em alguns dos trabalhos a natureza do tema parece ser conceitual, em outros, contextual.

Destaca-se que se entende por natureza conceitual temas os quais partem de conceitos para delimitar assuntos, ou que apresentem um tema como sendo o próprio conceito científico. Já por natureza contextual a premissa básica/primeira é o contexto, o problema, e a partir deles são delimitados os conceitos científicos. Admite-se que tais denominações derivam de Halmenschlager (2014, p. 147):

Os termos conceitual e contextual estão relacionados com a natureza do tema e com as articulações estabelecidas entre a conceituação científica e a temática. Assim, uma proposta conceitual, seja pontual ou de reestruturação curricular, estaria estruturada a partir de uma escolha, cuja temática se origina explicitamente da natureza conceitual das ciências, ou mesmo de um conceito em si, sendo este o ponto de partida para a organização das atividades. Já uma proposta contextual teria como ponto de partida para a organização das atividades de ensino um contexto, o qual pode contemplar distintas dimensões como social e/ou política, e cuja escolha não se restringe originalmente a um ou mais conceitos científicos específicos.

Considerando o Quadro 1 como exemplo de tema contextual, percebeu-se o trabalho 19, o qual discute a questão mais ampla do "Aquecimento global":

Um dos critérios de escolha foi a amplitude com que o tema era discutido na mídia, com grande influência e impacto na vida dos estudantes, seja por meio da televisão, rádio, Internet, jornal, revistas de divulgação científica, etc. (Trabalho 19, p. 5).

Em contraposição, artigos das atas dos primeiros Enpecs, como em alguns outros, a exemplo do Trabalho 9, apresentam temas de natureza mais conceituais:

No contexto da SE "Interconversões de energia em processos biofisicoquímicos", atenção especial foi dada ao conceito energia [...]. Sabe-se da natural dificuldade que os estudantes da Educação Básica possuem na compreensão de situações que envolvem energia. Este conceito representa uma grandeza não palpável, não modelável e nem "coisificável" e pode deixar a impressão de aparecer e desaparecer, instantaneamente, como o que ocorre ao se fechar e se abrir circuitos elétricos, implicando dificuldades de significação intrínseca ao conceito por exigir elevado grau de abstração.

\footnotetext{
Por natureza prática entende-se os trabalhos que se organizaram, construíram ou colocaram em prática alguma ação educativa, seja na educação básica ou na superior, abarcando - de algum modo - o processo de ensino/ aprendizagem com os sujeitos desses níveis (por exemplo, "professores", "estagiários", "alunos"). Por natureza teórica entende-se os trabalhos que visavam a discutir elementos, características e/ou referenciais que possam estar associados à perspectiva da SE.
} 
O fato de haver certa distinção, ou melhor, transição entre um tema dito "conceitual" para um "contextual" foi algo observado, por exemplo, por um professor entrevistado por Magoga (2017), quando o autor incitava as discussões entre a AT e SE. De acordo com o trabalho, o professor pertencente ao círculo esotérico: "também percebe que, ao longo dos anos, alguns elementos da $\mathrm{SE}$, relacionados às escolhas das temáticas, foram alterando-se, de forma que, hoje, a escolha dos temas parece estar mais contextual do que conceitual" (MAGOGA, 2017, p. 117).

Explicita-se que diferentes autores da área (AULER; DALMOLIN; FENALTI, 2009; STRIEDER; CARAMELLO; GEHLEN, 2010; DEMARTINI; SILVA, 2013), abordam que na AT o tema deve ser, necessariamente, contextual, isto é, deve partir de um contexto, de um meio, de um problema, e não de um conceito. O conceito, na perspectiva da AT, é subordinado ao tema.

O fato de a natureza do tema poder diferir entre as perspectivas de SE e AT talvez seja a explicação da principal característica percebida durante o processo de análise dos trabalhos do Quadro 1: apesar de abordarem suas ações a partir de temas, nenhum dos 28 artigos faz menção à perspectiva da AT. Isto é, os trabalhos que desenvolvem ações via SE não se caracterizam/identificam como uma AT.

Tal fato é importante, pois reforça a discussão da categoria anterior, em que se colocou a SE como uma perspectiva paralela à AT, e possibilita caracterizar melhor as ações em ambas as perspectivas. Há, todavia, um elemento importante nessa discussão, que deve ser aprofundado em trabalhos posteriores, a partir de diálogos com autores para problematizar, por exemplo, a recíproca percebida em trabalhos que versam sobre a AT, isto é, quem trabalha diretamente em uma perspectiva de AT e coloca a SE como uma modalidade desta.

Em suma, assim como efetuado na finalização da categoria anterior, sintetiza-se as informações discutidas ao longo da categoria "Os Temas na Situação de Estudo" no Quadro 3. Novamente reitera-se que o Quadro 3 não deve ser interpretado de modo descontextualizado às reflexões desta categoria.

Quadro 3 - Síntese da Categoria "Os Temas na Situação de Estudo"

\begin{tabular}{|l|l|}
\hline \multicolumn{1}{|c|}{ Situação de Estudo } & \multicolumn{1}{c|}{ Abordagem Temática } \\
\hline $\begin{array}{l}\text { Desenvolvimento dos trabalhos a partir de } \\
\text { temas }\end{array}$ & $\begin{array}{l}\text { Desenvolvimento dos trabalhos a partir de } \\
\text { temas }\end{array}$ \\
\hline $\begin{array}{l}\text { Natureza do tema pode ser conceitual ou } \\
\text { contextual }\end{array}$ & Natureza do tema é contextual \\
\hline Autores não a identificam como uma AT & $\begin{array}{l}\text { Autores identificam a SE como uma } \\
\text { modalidade de AT }\end{array}$ \\
\hline
\end{tabular}

Fonte: Os autores.

\section{Contextos de Produção da Situação de Estudo}

A última categoria de análise deste artigo é denominada "Contextos de Produção da SE" e carrega elementos que mostram, de certa forma, o surgimento da perspectiva da SE e como ela vem sendo trabalhada pela área. 
Dessa maneira, identificou-se grande importância do Grupo Interdepartamental de Pesquisa sobre Educação em Ciências (Gipec), seja em menção sobre ele - referindo-se ao pioneirismo do coletivo, sendo o precursor da perspectiva - ou sobre trabalhos desenvolvidos por integrantes e ex-integrantes dele mesmo.

A exemplificação das premissas anteriores é realizada a partir das seguintes unidades de significado:

Considerando as questões apontadas, trazemos para discussão ações e reflexões compartilhadas no coletivo de um grupo de professores e estudantes da Licenciatura (Biologia, Química e Física), vinculados ao Gipec-Unijuí e professores do Ensino Médio de uma Escola Estadual de ljuí (Trabalho 12, p. 3, grifo nosso).

O presente trabalho faz parte de um programa maior de pesquisa desenvolvido pelos professores/pesquisadores do Gipec-Unijuí. Procuramos explorar concepções teórico-epistemológicas, inseridas no debate atual sobre formação de professores e produção curricular na área de Ciências Naturais e suas Tecnologias, e propor novos níveis possíveis de entendimento de uma ação realizada na primeira série do Ensino Médio (Trabalho 6, p. 1, grifo nosso).

O Gipec originou-se por meio de projetos-piloto os quais buscavam discutir ações pedagógicas inovadoras. Com o andamento das pesquisas, o olhar dos integrantes do grupo foi se expandido, entendendo a necessidade de articulação/diálogo entre a universidade e a escola básica com intenção de ampliar os laços entre a formação inicial e continuada de professores. A partir dessa interação, focada na organização dos conteúdos escolares, emergiram discussões sobre produções curriculares centradas em SE (VIEIRA, 2017).

Alinhado neste viés, o Trabalho 1, elaborado por integrantes do próprio Gipec, contém uma descrição que apesar de longa é bastante elucidativa:

Dentro do Gipec-Unijuí, na tentativa de produzir um entendimento do que seja a Educação Básica na formação dos adolescentes, vendo-a muito mais do que um simples trampolim para a Educação Universitária, aceitamos as duas ideias básicas desenvolvidas no contexto das pesquisas construtivistas dos anos 70/80: 1. os alunos chegam à escola com muitas ideias e explicações acerca dos fenômenos naturais e dos princípios de funcionamento dos produtos tecnológicos com os quais convivem em seu dia a dia; 2 . as ideias e explicações dos alunos desempenham importante papel na aprendizagem das ciências buscadas na escola e, por isso, não podem ser desconsideradas nas propostas pedagógicas (Trabalho 1, p. 4).

Apesar de fundamentadas em ideais dos anos 70/80, a caracterização, o desenvolvimento das ações do que hoje se apresenta como SE começou no início dos anos 2000, com o próprio Gipec. Diferentemente, portanto, da AT, a qual teve sua concepção originada em outro grupo e em outro momento histórico, anterior à SE.

Como discutido no referencial deste artigo, a AT teve seu início a partir do Grupo de Reelaboração de Conteúdo e Formação de Professores, do Instituto de Física da USP (PIERSON, 1997). A gênese da perspectiva que hoje é AT, portanto, é anterior aos anos 2000, remetendo a trabalhos dos anos 80 e 90. 
Ademais, o referencial epistemológico de ambas as perspectivas, justamente por serem originadas em grupos diferentes, é distinto. Enquanto o Grupo de Reelaboração de Conteúdo e Formação de Professores fundamentou-se em Freire, o Gipec ampara-se no referencial vigotskiano, como descrito - ainda que brevemente em alguns - nos 28 trabalhos do Quadro 1. Para Halmenschlager (2010, p. 37), a escolha por esse referencial ocorreu por que há elementos da abordagem histórico-cultural que podem auxiliar a construção de um currículo e que, portanto, "venha ao encontro da formação de um aluno capaz de compreender o mundo que o cerca e estabelecer relações entre conhecimento cotidiano e conhecimento científico [...]"

Outro importante aspecto relacionado ao contexto de produção das SE refere-se aos sujeitos envolvidos, ou melhor, não aos sujeitos em si, mas à interação entre os coletivos de sujeitos. Constatou-se que o trabalho colaborativo entre as formações iniciais, continuadas, e os grupos de pesquisa, é uma característica importante e recorrente nessa perspectiva. Na sequência são apresentadas unidades representativas:

Esse texto resultou de uma pesquisa, que pretende integrar a formação iniciale continuada de professores, ao analisar a SE "Alimentos: Produção e Consumo", desenvolvida no componente curricular de Ciências II, do Curso de Ciências-Licenciatura Plena com Habilitação em Ciências no Ensino Fundamental e Biologia ou Química, no Ensino Médio (Trabalho 3, p. 2, grifo nosso).

Nesse sentido, buscamos produzir interações, com a intenção de reorganização do currículo escolar, na forma de Situação de Estudo (SE), as quais se configuram como um espaço rico de trabalho colaborativo, envolvendo formadores da universidade, professores de escola e estudantes de licenciatura (Trabalho 12, p. 2, grifo nosso).

A articulação entre estas três "classes" (Grupo, Formação Inicial e Formação Continuada) é singular e fundamental, pois possibilita trocas de conhecimentos e experiências, especialmente por estarem associadas à construção de currículos - como objetiva a SE. Vieira et al. (2017) explicitam que as ações envolvendo a interação entre tais coletivos, ou de forma macro, entre a Educação Superior e a Educação Básica, são benéficas também ao aluno desta última, pois o processo de ensino/aprendizagem passa a ser objeto de discussão e reinvenção.

Além disso, tal forma de ação é diferente da desenvolvida por trabalhos que abordam a AT pois, de acordo com Magoga (2017), nesses casos as ações têm sido versadas entre Grupos e Formação Inicial ou Grupos e Formação Continuada. A articulação, em trabalhos conjuntos - de forma mais sistemática - entre as três "classes", tal qual já ocorre na SE, ainda é incipiente e almejada por pesquisadores da AT.

Sendo assim, os elementos abordados nessa categoria envolvendo os contextos de produção da SE e das relações destes com a AT podem ser observados, de modo resumido, no Quadro 4 (destaca-se que a interpretação deste quadro deve estar ancorada nas discussões apresentadas na categoria). 
Quadro 4 - Síntese da Categoria "Contextos de Produção da Situação de Estudo"

\begin{tabular}{|l|l|}
\hline \multicolumn{1}{|c|}{ Situação de Estudo } & \multicolumn{1}{c|}{ Abordagem Temática } \\
\hline $\begin{array}{l}\text { Produção e disseminação da proposta por } \\
\text { integrantes do Gipec. }\end{array}$ & $\begin{array}{l}\text { Produção pelo Grupo de Reelaboração de } \\
\text { Conteúdo e Formação de Professores e } \\
\text { disseminação por diferentes sujeitos. }\end{array}$ \\
\hline Referencial baseado em Vygotsky. & Referencial baseado em Freire. \\
\hline $\begin{array}{l}\text { Trabalho colaborativo entre a Formação } \\
\text { Inicial, Continuada e Grupo de Pesquisa. }\end{array}$ & $\begin{array}{l}\text { Em muitos casos, limita-se ao trabalho de } \\
\text { Grupos de Pesquisa com a Formação Inicial } \\
\text { ou Formação Continuada. }\end{array}$ \\
\hline
\end{tabular}

Fonte: Os autores.

\section{CONSIDERAÇÕES FINAIS}

O presente estudo foi elaborado partindo de antagonismos e necessidades apontadas por alguns trabalhos da área de ensino de Ciências, os quais, ao mesmo tempo, salientam a importância e recorrência de duas perspectivas de conceber e executar currículos, a SE e a AT. Os resultados, descritos por meio das categorias "Situação de Estudo Enquanto Proposta de Organização Curricular", "Os Temas na Situação de Estudo" e "Contextos de Produção da Situação de Estudo", mostraram que existem semelhanças e diferenças entre as referidas perspectivas.

Da primeira categoria constatou-se que a SE é entendida como uma perspectiva de currículo ampla, a qual possui reflexos tanto no modo de conceber quanto de executar currículos, assim como na AT. Ambas as perspectivas, por exemplo, trabalham com a ideia de um ensino contextualizado e interdisciplinar. A questão interdisciplinar, entretanto, na AT, possui uma menção aos trabalhos entre as diferentes áreas do conhecimento, não apenas entre as disciplinas. Já na perspectiva da SE, o trabalho interdisciplinar entre as áreas não é objeto de extensa discussão, tendo em vista que há uma forte característica deste trabalho ser desenvolvido, de modo sistemático, entre as disciplinas da área das Ciências da Natureza.

Na segunda categoria, tendo certa associação com os aspectos discutidos anteriormente, verificou-se que na SE são desenvolvidos temas os quais podem ter origem de natureza conceitual ou contextual, diferindo, em certo sentido, da AT, em que se trabalha por temas, mas estes necessariamente possuem origem contextual. Ainda, uma importante percepção foi a de que autores da SE não descrevem que ela é uma perspectiva de $\mathrm{AT}$, enquanto que alguns pesquisadores dessa última a colocam como uma modalidade específica.

Por último, na apresentação dos contextos de produção da SE, discorreu-se sobre a sua origem e disseminação, a qual está muito atrelada ao Gipec da Unijuí, e tem como referencial primeiro Lev Vygotsky, fundamentando-se na abordagem histórico-cultural. Diferentemente, a AT tem sua origem pelo grupo de Reelaboração de Conteúdo e Formação de Professores, epistemologicamente baseia-se em Paulo Freire e é temporalmente antecessora da SE. Ainda nessa análise, percebeu-se que a SE caracteriza-se por ter um trabalho integrado entre três segmentos: grupos de pesquisa, formação inicial e 
formação continuada. Já a AT carece dessa peculiaridade, pois se identifica que as ações estão voltadas, majoritariamente, às dualidades grupos-formação inicial e grupos-formação continuada.

Apesar de este estudo conter relevantes informações e caracterizações, entende-se que sejam necessários outros trabalhos os quais aprofundem a análise acerca dessas concepções e das correlações com os currículos escolares. Esses novos estudos são importantes pois, além de mostrar as fronteiras entre ambas as perspectivas, podem sinalizar caminhos que os aproximem ainda mais, potencializando os processos de ensino/aprendizagem na Educação Básica e na Educação Superior, especialmente na busca de reestruturações curriculares.

Ainda, como continuidade, recomenda-se que as análises teóricas continuem buscando atas de outros eventos - a exemplo dos Simpósios Nacionais de Ensino de Física, Encontros Nacionais de Ensino de Biologia e Encontros Nacionais de Ensino de Química - mas, principalmente, que ocorram diálogos diretos, via entrevistas, com autores e pesquisadores da área que trabalhem diretamente com a SE. A busca pelo contato pode facilitar entender as relações teóricas entre as perspectivas e ajuda a esclarecer, por exemplo, o fato de nenhum trabalho ter se identificado como uma modalidade de AT.

Ao final deste artigo reitera-se, portanto, que a apresentação dos resultados não buscou realizar uma separação "antidialógica" entre as duas perspectivas, mas apenas caracterizar - como apresentado ao longo do texto - espaços específicos de cada uma, isto é, sinalizando limites entre ambas.

\section{REFERÊNCIAS}

AULER, D. Alfabetização científico-tecnológica: um novo "paradigma"? Ensaio - Pesquisa em Educação em Ciências, v. 5, n. 1, mar. 2003.

AULER, D.; DALMOLIN, A. M. T.; FENALTI, V. Abordagem temática: natureza dos temas em Freire e no enfoque CTS. Alexandria: Revista de Educação em Ciência e Tecnologia, v. 2, n. 1, p. 67-84, 2009.

AUTH, M. A. Formação de professores de ciências naturais na perspectiva temática e unificadora. 2002. 250f. Tese (Doutorado em Educação) - Universidade Federal de Santa Catarina, Programa de Pós-Graduação em Educação, Florianópolis/SC, 2002.

BRASIL. Lei no 9.394, de 20 de dezembro de 1996. Lei de Diretrizes e base da Educação Nacional. Brasília, 1996.

BRASIL. Ministério da Educação. Secretaria de Educação Média e Tecnológica. Parâmetros Curriculares Nacionais Ensino Médio. Brasília: MEC, 2000.

BRASIL. Diretrizes curriculares gerais da educação básica. 562 p. Brasília: Ministério da Educação; Secretaria de Educação Básica; Diretoria de Currículos e Educação Integral, 2013.

BRASIL. Ministério da Educação. Base Nacional Comum Curricular. Brasília: MEC, 2018.

CENTA, F. G. et al. Práticas educativas baseadas na abordagem temática: uma análise dos trabalhos no XIII e XX SNEFs. In: SIMPÓSIO NACIONAL DE ENSINO DE FÍSICA, 21, 2015, Uberlândia. Anais Eletrônicos [...]. Uberlândia, MG: Sociedade Brasileira de Física, 2015. Disponível em: http://www.sbf1.sbfisica.org. br/eventos/snef/xxi/sys/resumos/T0122-1.pdf. Acesso em: 3 dez. 2017.

DELIZOICOV, D.; ANGOTTI, J. A.; PERNAMBUCO, M. M. C. A. Ensino de ciências: fundamentos e métodos. 4. ed. São Paulo: Cortez, 2011.

DEMARTINI, G. R.; SILVA, A. F. G. Abordagem temática na sistematização curricular para o ensino de ciências: gravidez na adolescência em uma escola estadual do município de Sorocaba-SP. In: ENCONTRO NACIONAL DE PESQUISA EM EDUCAÇÃO EM CIÊNCIAS, 9., 2013, Águas de Lindoia. Atas [...]. Águas de Lindoia, 2013. 
FERREIRA, M. V. Intervenções curriculares estruturadas a partir da abordagem temática: desafios e potencialidades. 2016. Dissertação (Mestrado em Educação em Ciências) - Universidade Federal de Santa Maria, Santa Maria, 2016.

FLECK, L. Gênese e desenvolvimento de um fato científico. Belo Horizonte, MG: Fabrefactum, 2010.

FRISON, M. D. A produção de saberes docentes articulada à formação inicial de professores de Química: implicações teórico-práticas na escola de nível médio. 2012. 310f. Tese (Doutorado em Educação) - Universidade Federal do Rio Grande do Sul, Curso de Pós-Graduação em Educação em Ciências: Química da Vida e da Saúde, Porto Alegre, 2012.

GEHLEN, S. T. A função do problema no processo ensino-aprendizagem de ciências: contribuições de Freire e Vygotsky. 2009. 254f. Tese (Doutorado em Educação Científica e Tecnológica) - Universidade Federal de Santa Catarina, Florianópolis, SC, 2009.

GEHLEN, S. T. et al. A inserção da abordagem temática em cursos de licenciatura em Física em instituições de ensino superior. Investigações em Ensino de Ciências (UFRGS. Impresso), v. 19, p. 155-175, 2014.

GIACOMINI, A.; MUENCHEN, C. Os avanços construídos num processo formativo de professores balizados pela abordagem temática. Educação Online, Rio de Janeiro, n. 24, p. 51-73, jan./abr. 2017.

GIL, A. C. Como elaborar projetos de pesquisa. 5. ed. São Paulo: Atlas, 2010.

HALMENSCHLAGER, K. R. Abordagem de temas em ciências da natureza no ensino médio: implicações na prática e na formação docente. 2014. 373f. Tese (Doutorado em Educação Científica e Tecnológica) - Universidade Federal de Santa Catarina, Florianópolis, SC, 2014.

HALMENSCHLAGER, K. R. Abordagem temática: análise da situação de estudo no Ensino Médio da EFA. 2010. 181f. Dissertação (Mestrado em Educação Científica e Tecnológica) - Universidade Federal de Santa Catarina, Florianópolis, SC, 2010.

HALMENSCHLAGER, K. R. Abordagem temática no ensino de ciências: algumas possibilidades. Vivências: Revista Eletrônica de Extensão da URI, Erechim, RS, v. 7, n. 13, p. 10-21, out. 2011.

HUNSCHE, S. Professor "fazedor" de currículos: desafios no estágio curricular supervisionado em ensino de física. 2010. 143f. Dissertação (Mestrado em Educação) - Universidade Federal de Santa Maria, Santa Maria, 2010.

HUNSCHE, S.; DELIZOICOV, D. A abordagem temática na perspectiva da articulação Freire-CTS: um olhar para a instauração e disseminação da proposta. ENCONTRO NACIONAL DE PESQUISA EM EDUCAÇÃO EM CIÊNCIAS, 8., 2011, Campinas. Atas [...]. Campinas, SP, 2011.

MAGOGA, T. F. Abordagem temática na educação em ciências: um olhar à luz da epistemologia fleckiana. 2017. 167f. Dissertação (Mestrado em Educação em Ciências) - Universidade Estadual de Santa Maria, Programa de Pós-Graduação em Educação em Ciências: Química da Vida e Saúde, Santa Maria, 2017.

MAGOGA, T. et al. Uma análise das práticas educativas baseadas na abordagem temática nas atas dos ENPECs. In: SEMINÁRIO INTERNACIONAL DE EDUCAÇÃO EM CIÊNCIAS, 3., 2014, Rio Grande, RS, 2014.

MAGOGA, T; MUENCHEN, C. Abordagem Temática: um olhar sobre os pesquisadores dessa perspectiva curricular. In: SIMPÓSIO NACIONAL DE ENSINO DE FÍSICA, 22., 2017, São Carlos, SP: Sociedade Brasileira de Física, 2017.

MALDANER, O. A. Situações de Estudo no Ensino Médio: nova compreensão de educação básica. In: NARDI, Roberto (org.). A pesquisa em ensino de ciências no Brasil: alguns recortes. 1. ed. São Paulo: Escrituras, 2007. p. 241-256. V. único.

MALDANER, O. A.; COSTA-BEBER, L. B.; MACHADO, A. R. Desenvolvimento e aprendizagem de conceitos biofisicoquímicos em uma Situação de Estudo: mapa conceitual e metaconceitual como instrumentos de investigação. Alexandria: Revista de Educação em Ciência e Tecnologia, v. 5, n. 1, p. 85-111, maio 2012.

MALDANER, O. A.; ZANON, L. B. Situação de estudo: uma organização do ensino que extrapola a formação disciplinar em ciências. Revista Espaços da Escola, ljuí: Ed. Unijuí, n. 41, p. 44, 2001.

MENEZES, L. C. Novo (?) Método (?) Para ensinar (?) Física (?). Revista Brasileira de Ensino de Física, v. 2, n. 2, 1980.

MORAES. R.; GALIAZZI, M. C. Análise textual discursiva. Ijuí: Editora Unijuí, 2007.

MUENCHEN, C. Configurações curriculares mediante o enfoque CTS: desafios a serem enfrentados na EJA. 2006. 129f. Dissertação (Mestrado em Educação) - Universidade Federal de Santa Maria, Santa Maria, 2006.

MUENCHEN, C.; AULER, D. Configurações curriculares mediante o enfoque CTS: desafios a serem enfrentados na Educação de Jovens e Adultos. Ciência \& Educação, v. 13, p. 421-434, 2007.

MUENCHEN, C.; DELIZOICOV, D. Os três momentos pedagógicos e o contexto de produção do livro "física". Ciência \& Educação, v. 20, n. 3, p. 617-638, 2014. 
PANSERA-DE-ARAÚJO, M. C.; AUTH, M. A.; MALDANER, O. A. Autoria compartilhada na elaboração de um currículo inovador em ciências no Ensino Médio. Contexto \& Educação, ljuí, v. 22, n. 77, p. 241-262, jan./ jun. 2007.

PIERSON, A. H. C. O cotidiano e a busca do sentido para o ensino de Física. 1997. Tese (Doutorado em Educação) - Faculdade de Educação, Universidade de São Paulo, São Paulo, 1997.

SANGIOGO, F. A. et al. Pressupostos epistemológicos que balizam a Situação de Estudo: algumas implicações ao processo de ensino e à formação docente. Ciência \& Educação, v. 19, n. 1, p. 35-54, 2013.

SCHNEIDER, T. M. et al. Abordagem temática em sala de aula: uma análise dos trabalhos apresentados no I, VIII e IX ENPECs. In: ENCONTRO DE PESQUISA EM ENSINO DE FÍSICA, 15., 2014, Maresias. Anais eletrônicos [...]. Maresias, SP: Sociedade Brasileira de Física, 2014. Disponível em: http://www.sbf1.sbfisica.org. br/eventos/epef/xv/sys/resumos/T0079-1.pdf. Acesso em: 3 jan. 2017.

SILVA, T. T. Documentos de identidade: uma introdução às teorias do currículo. Belo Horizonte: Autêntica, 2011.

STRIEDER, R. B.; CARAMELLO, G. W.; GEHLEN, S. T. Abordagem de temas no Ensino Médio: compreensões de professores de física. In: ENCONTRO DE PESQUISA EM ENSINO DE FÍSICA, 12., 2010, Águas de Lindoia. Anais eletrônicos [...]. Águas de Lindoia, SP: Sociedade Brasileira de Física, 2010. Disponível em: http:// www.sbf1.sbfisica.org.br/eventos/epef/xii/sys/resumos/T0117-1.pdf. Acesso em: 3 dez. 2017.

VIEIRA, L; B. G. Situação de Estudo: compreensões dos formadores de professores do ensino de ciências. 2017. 121f. Dissertação (Mestrado em Educação em Ciências) - Universidade Estadual de Santa Cruz, Programa de Pós-Graduação em Educação em Ciências, Ilhéus, 2017.

VIEIRA, L. B. G. et al. Situação de Estudo: tendências de teses e dissertações na área de Ensino de Ciências. In: ENCONTRO NACIONAL DE PESQUISA EM EDUCAÇÃO EM CIÊNCIAS, 11., 2017, Florianópolis, SC, 2017. 